H. LEWANDOWSKI, R, SUSZKKO

\title{
W SPRAWIE TEORII DESKRYPTÓW
}

(Streszczenie)

W pracy przedstawia się podstawowe własności operatora deskrypcyjnego wprowadzonego przez P. Bernaysa (P. Bernays and A. A. Fraenkel, Axiomatic Set Theory, Amsterdam 1958).

Wyrażenie $L x(\mathrm{p}[x] ; \mathrm{t})$ oznacza ten jedyny przedmiot $x$ taki, że $\mathrm{p}[x]$ lub też $t$, o ile takiego przedmiotu $x$ nie ma. Term t zapewnia wykonalność operacji deskrypcji dla dowolnych formul $\mathrm{p}$.

Praca jest uzupełnieniem zestawienia własności różnych teorii deskrypcji podanego przez R. Montague'a i D. Kalisha w artykule Remarks on descriptions and natural deduction (Archiv für mathematische Logik und Grundlagenforschung, Heft 3/1-2, 50-64).

\author{
Х. ЛЕВАНДОВСКИ, Р. СУШКО \\ ОТНОСИТЕЛЬНО ТЕОРИИ ДЕСКРИПЦИЙ
}

(P е 3 ro $\mathrm{Me}$ )

В статье представлены основные свойства дескриптивного оператора, введенного П. Бернайсом (P. Bernays and A.A. Fraenkel, Axiomatic Set Theory, Amsterdam 1958).

Выражение $L x(\mathrm{P}[x] ; \mathrm{t})$ обозначает тот единственный объект $x$ такой, qто $\mathrm{P}[x]$ или же $\mathrm{t}$, если такого объекта $x$ нет. Терм $\mathrm{t}$ гарантирует выполняемость операции дескришции для произвольных формул $\mathrm{p}$.

Настояцая работа является дополнением к сопоставлению свойств различных теорий дескритщий, данных Р. Монтегю и Д. Кэлишем в статье Remarks on descriptions and natural deduction (Archiv für mathematische Logik und Grundlagenforschung, Heft 3/1-2, 50-64). 